\title{
Characterization of Sputter Deposited Thin Film Scandate Cathodes for Miniaturized Thermionic Converter Applications
}

\author{
Kevin R. Zavadil, Judith H. Ruffner, and Donald B. King \\ Sandia National Laboratories, Materials \& Processing Sciences Center, Albuquerque, NM 87185-0340 \\ 505-845-8442, krzavad@sandia.gov
}

\begin{abstract}
We have successfully developed a method for fabricating scandate-based thermionic emitters in thin film form. The primary goal of our effort is to develop thin film emitters that exhibit low work function, high intrinsic electron emissivity, minimum thermal activation properties and that can be readily incorporated into a microgap converter. Our approach has been to incorporate $\mathrm{BaSrO}$ into a $\mathrm{Sc}_{2} \mathrm{O}_{3}$ matrix using if sputtering to produce thin films. Diode testing has shown the resulting films to be electron emissive at temperatures as low as $900 \mathrm{~K}$ with current densities of $0.1 \mathrm{~mA} \cdot \mathrm{cm}^{-2}$ at $1100 \mathrm{~K}$ and saturation voltages. We calculate an approximate maximum work function of $1.8 \mathrm{eV}$ and an apparent emission constant (Richardson's constant, $\mathrm{A}^{*}$ ) of $36 \mathrm{~mA} \cdot \mathrm{cm}^{-2} \cdot \mathrm{K}^{-2}$. Film compositional and structural analysis shows that a significant surface and subsurface alkaline earth hydroxide phase can form and probably explains the limited utilization and stability of $\mathrm{Ba}$ and its surface complexes. The flexibility inherent in sputter deposition suggests alternate strategies for eliminating undesirable phases and optimizing thin film emitter properties.
\end{abstract}

\section{INTRODUCTION}

Our goal is to develop a low temperature, stable, thin film thermionic emitter for integration into Sandia National Laboratories' microthermionic converter (King, 1995). Traditional low temperature emitters are based on stabilized barium strontium oxide (BSCO $-47.5 \% \mathrm{Ba}, 47.5 \% \mathrm{Sr}$ and $5 \% \mathrm{Ca}$ ) (Thomas, 1990). Saito et al. have shown that depositing a capping layer of scandia $\left(\mathrm{Sc}_{2} \mathrm{O}_{3}\right)$ improves the longevity of traditional BSCO emitters (Saito, 1990). The role of scandia has been recognized for some time in higher operating temperature tungsten based dispenser cathodes (Gartner, 1997). The primary problem with BSCO films is that deposition from carbonate precursors is required with a subsequent activation stage that releases $\mathrm{CO}_{2}$, trapped $\mathrm{H}_{2} \mathrm{O}$ and suboxides. This activation process is responsible for producing the emitting oxide, which has a very low activation energy for free $\mathrm{Ba}$ production and is easily "poisoned" with subsequent atmospheric exposure. As a result, activation must be conducted in the diode environment, which results in the production of high levels of condensable gases. We have found that the sorption of these gases onto the internal surface area of the diode produces unacceptable values of leakage current between emitter and collector. RF sputtering eliminates the need for formal activation because oxides can be directly deposited in thin film form. In addition, sputtering allows for grading the film structure, tailoring the oxide nonstoichiometry to facilitate free Ba production, and directly capping with a scandia overlayer. In this paper, we report on our initial results for tailored scandate thin film deposition and their resulting diode characteristics.

\section{EXPERIMENTAL}

Films were deposited in a Unifilm PVD300 of sputtering system from BSCO (47.5:47.5:5\%) and $\mathrm{Sc}_{2} \mathrm{O}_{3}$ targets (Plasmaterials, Pleasanton, CA). Four inch Si wafers capped by a $400 \mathrm{~nm}$ thermal oxide served as a substrate. Thirty $\mathrm{nm}$ of Ti followed by $500 \mathrm{~nm}$ of Ta were deposited as a base electrode. A bi-layer consisting of $150 \mathrm{~nm}$ to $1 \mu \mathrm{m}$ of BSCO with a 200 to $400 \mathrm{~nm} \mathrm{Sc} \mathrm{O}_{3}$ cap were then deposited on the metallized wafer. Deposition rates of 10 to 20 $\mathrm{nm} / \mathrm{min}$ were used with substrate temperatures ranging from 298 to $873 \mathrm{~K}$. Oxygen, at pressures of several mtorr, was added to the plasma to offset the nonstoichiometry generated by ion bombardment. The resulting films were characterized using optical and electron microscopy (Hitachi S4500, field emitter source), x-ray diffraction (Siemens D500), and x-ray photoelectron (Physical Electronics 5400, $300 \mathrm{~W} \mathrm{Mg}(\mathrm{K} \alpha)$ ) and fluorescence (Princeton Gamma-Tech) spectroscopies. The wafers were scribed into approximately $10 \times 17 \mathrm{~mm}$ coupons and mounted onto a 


\section{DISCLAIMER}

This report was prepared as an account of work sponsored by an agency of the United States Government. Neither the United States Government nor any agency thereof, nor any of their employees, make any warranty, express or implied, or assumes any legal liability or responsibility for the accuracy, completeness, or usefulness of any information, apparatus, product, or process disclosed, or represents that its use would not infringe privately owned rights. Reference herein to any specific commercial product, process, or service by trade name, trademark, manufacturer, or otherwise does not necessarily constitute or imply its endorsement, recommendation, or favoring by the United States Government or any agency thereof. The views and opinions of authors expressed herein do not necessarily state or reflect those of the United States Government or any agency thereof. 


\section{DISCLAIMER}

Portions of this document may be illegible in electronic image products. Images are produced from the best available original document. 
resistively heated manipulator of an ultrahigh vacuum chamber, as previously described (Zavadil, 1996). A Mo foil collector was mounted on an opposing manipulator to form a vacuum diode circuit with an adjustable gap. The emitter was held at ground and the collector current was monitored as a function of bias voltage using a Keithley 283 high current multimeter interfaced to a personal computer. The emitter and collector could be separated, repositioned in front of a cylindrical mirror analyzer (Physical Electronics, 10-155), and evaluated using Auger electron spectroscopy.

\section{RESULTS AND DISCUSSION}

A variety of thin bi-layers films have been deposited onto a $\mathrm{Ta} / \mathrm{Ti}$ electrode on $\mathrm{Si}$, as given in Table 1 . Figure 1 shows a cross-section secondary electron micrograph of one of these films (Therm-7) generated by fracturing the Si substrate wafer. We observe four discrete layers sitting on top of the Si substrate: 1) $400 \mathrm{~nm}$ of thermally grown $\mathrm{SiO}_{2}$, 2) $500 \mathrm{~nm}$ of sputter deposited $\mathrm{Ta}$ (Ti layer is not resolved) as an electrode, 3) <400 nm of BSCO and 4) 400 $\mathrm{nm}$ of $\mathrm{Sc}_{2} \mathrm{O}_{3}$. The microscopy shows that continuous bi-layer structures $\left(\mathrm{BSCO} / \mathrm{Sc}_{2} \mathrm{O}_{3}\right)$ can be sputter deposited. The figure also shows that the $\mathrm{BSCO}$ layer forms platelet crystals oriented parallel to the surface and $\mathrm{Sc}_{2} \mathrm{O}_{3}$ forms columnar crystals oriented perpendicular to the substrate. The films have a specular surface finish when first removed from vacuum, but develop surface texture with exposure to atmosphere. We have found that thicker scandia capping layers, elevated temperature deposition $(573 \mathrm{~K})$ and introduction $\mathrm{Of}_{2}$ into the rf plasma all slow the development of this surface texture. Mass gain measurements made on wafers as a function of post-deposition atmospheric exposure are consistent with the uptake of $\mathrm{H}_{2} \mathrm{O}$ to form a hydroxide phase. We believe that the columnar scandia crystal structure is largely responsible for the high permeability to $\mathrm{H}_{2} \mathrm{O}$ and subsequent hydroxide formation.

TABLE 1. Variation in Process Conditions between Thin Film Emitters

\begin{tabular}{|c|c|c|c|c|}
\hline Sample & BSCO thickness (nm)* & $\mathrm{Sc}_{2} \mathrm{O}_{3}$ thickness $(\mathrm{nm})^{*}$ & Temperature (K) & $\mathrm{O}_{2}$ Pressure (mtorr) \\
\hline Therm-2 & 1000 & 2000 & 298 & --- \\
\hline Therm-4 & 1000 & 2000 & 573 & -- \\
\hline Therm-5 & 1000 & 2000 & 298 & 2.5 \\
\hline Therm- 6 & 1000 & 2000 & 873 & 2.5 \\
\hline Therm-7 & 1000 & 4000 & 573 & 2.5 \\
\hline Therm-8 & 150 & 2000 & 573 & 2.5 \\
\hline
\end{tabular}

*target thickness values

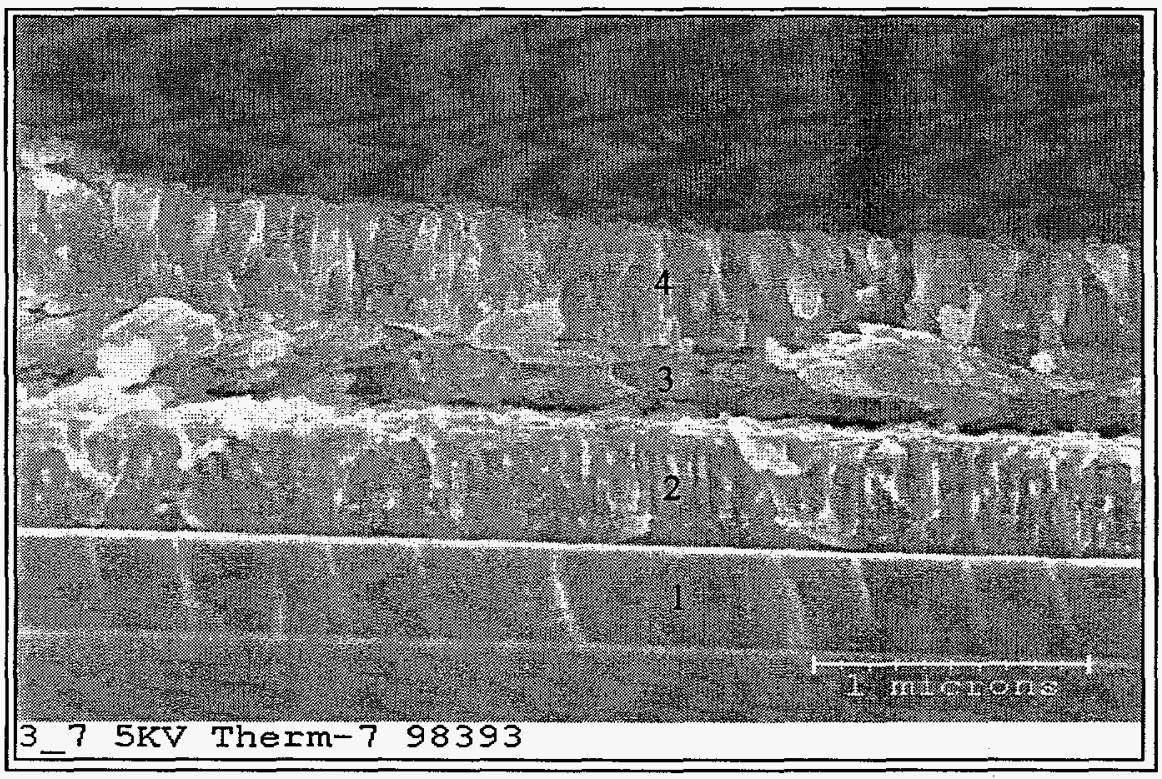

FIGURE 1. Cross-section SEM of a BSCO/Sc $\mathrm{O}_{3}$ emitter - 1) thermal $\mathrm{SiO}_{2}, 2$ ) $\mathrm{Ta}$ Ti electrode, 3) BSCO layer and 4) $\mathrm{Sc} \mathrm{O}_{3}$ cap. 
Surface spectroscopy has been used to verify the existence of hydroxide. X-ray photoelectron spectroscopy shows that $\mathrm{Ba}$ and $\mathrm{Sr}$ are always present on the surface of these films, despite the structure termination with the capping scandia layer. Figure 2 shows the relative near surface concentrations for a series of films as a function of deposition

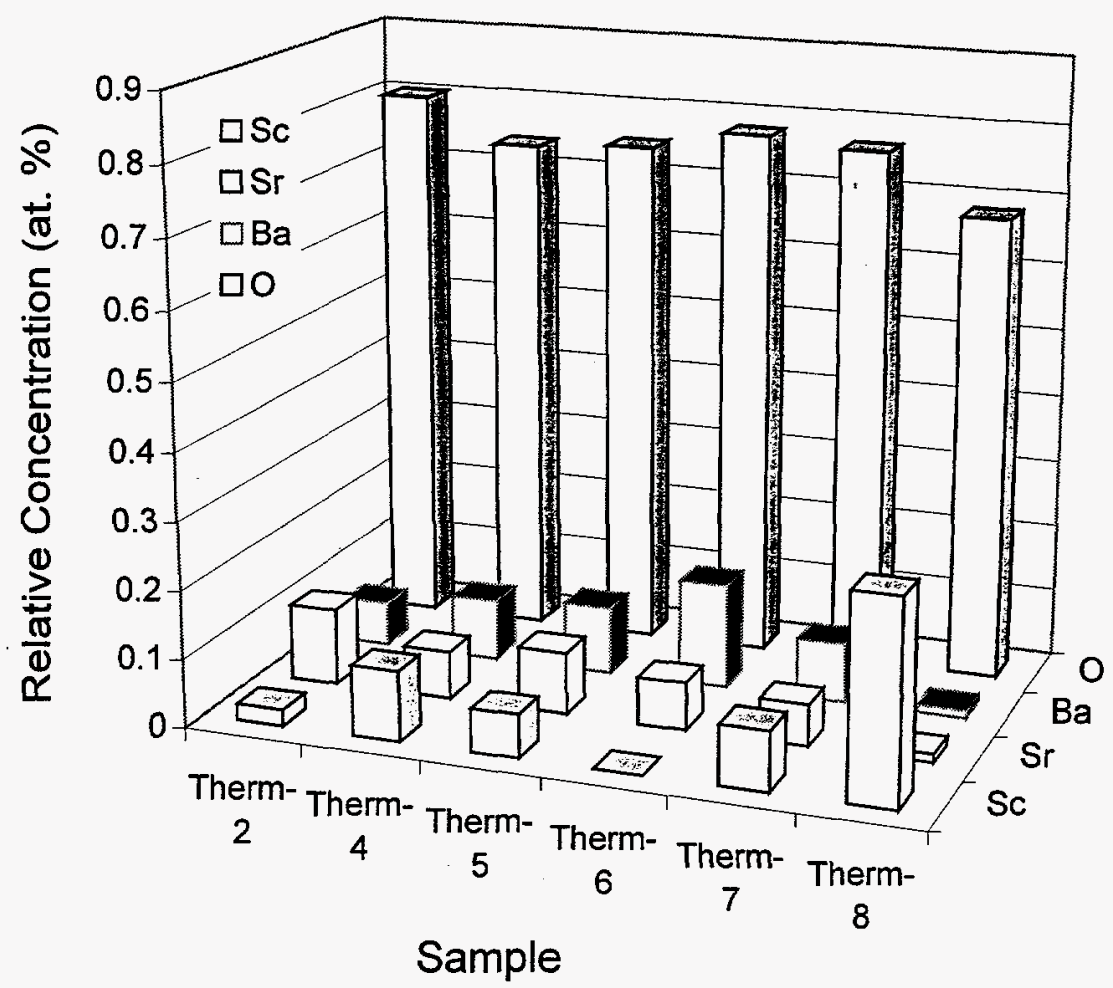

FIGURE 2. Variation in surface composition of $\mathrm{BSCO} / \mathrm{Sc}_{2} \mathrm{O}_{3}$ bi-layer emitters with rf deposition conditions - Therm-2 at 298 $\mathrm{K}$ without $\mathrm{O}_{2}$, Therm- 4 at $573 \mathrm{~K}$ without $\mathrm{O}_{2}$, Therm-5 at $298 \mathrm{~K}$ with $\mathrm{O}_{2}$, Therm- 6 at $873 \mathrm{~K}$ with $\mathrm{O}_{2}$, Therm-7 at $573 \mathrm{~K}$ with $\mathrm{O}_{2}$ and a thicker scandia overlayer, Therm- 8 at $573 \mathrm{~K}$ with $\mathrm{O}_{2}$ and a thinner BSCO layer (see Table 1).

conditions. The $O(1 \mathrm{~s})$ lineshape from photoelectron spectroscopic measurements shows two features separated in energy by approximately $2.3 \mathrm{eV}$, consistent with emission from a more electronegative oxide and a more electropositive hydroxide. The relative hydroxide to oxide surface concentration (not shown in Figure 2) scales with the amount of surface $\mathrm{Ba}$ and $\mathrm{Sr}$. This finding argues that these species are being transported through the scandia overlayer due to the activity of $\mathrm{H}_{2} \mathrm{O}$. The data of Figure 2 also demonstrates that the lowest degree of $\mathrm{Ba}$ and $\mathrm{Sr}$ conversion and transport are achieved with deposition at temperature, in oxygen and with thicker capping layers.

Cross-section SEM analysis shows that the hydroxide conversion is spatially localized. Figure 3 shows an adjacent portion of the same sample shown in Figure 1. In this figure, we find that a surface feature several microns in height has been intersected by the fracture. Using energy dispersive $\mathrm{x}$-ray fluorescence, we are able to collect compositional information from each of the discrete layers and features shown in Figure 3. We find that the scandia capping layer is still intact below and to either side of the surface feature. We also find that the relative $\mathrm{O} K$ shell emission from $\mathrm{x}$-ray fluorescence is significantly greater in the surface feature than either the underlying $\mathrm{Sc}_{2} \mathrm{O}_{3}$ or BSCO. This observation is direct evidence that hydroxide formation is spatially localized to the surface feature. To the right of this same image, we see a bulging of the BSCO and scandia layers and once again a high relative $O$ signal in the BSCO. We conclude that $\mathrm{H}_{2} \mathrm{O}$ ingress occurs locally, first permeating and forming an underlayer hydroxide and then hydrating to an extent where transport of $\mathrm{Ba}^{2+}$ and $\mathrm{Sr}^{2+}$ through the scandia is possible. Hydroxide phase formation then continues locally at the surface. 


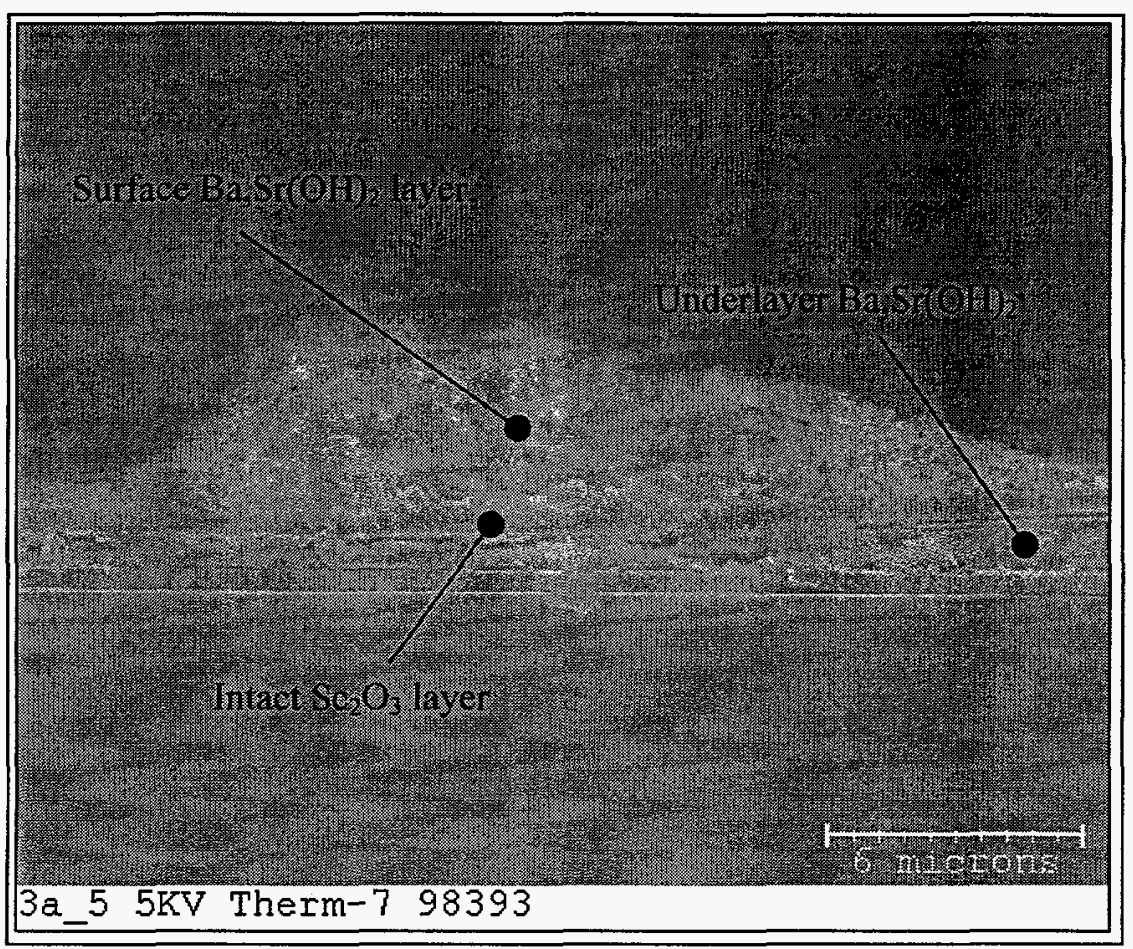

FIGURE 3. Cross-section micrograph showing surface and subsurface hydroxide phase for sample Therm-7.

The hydroxide is a potentially undesirable phase because electron emission would not be occurring exclusively from a $\mathrm{Ba}-\mathrm{Sc}_{2} \mathrm{O}_{3}$ surface complex. We find that these films are electron emissive. Figure 4 shows the current vs. voltage response for Therm-7 at various temperatures using a Mo collector. This data was collected in vacuum at a pressure

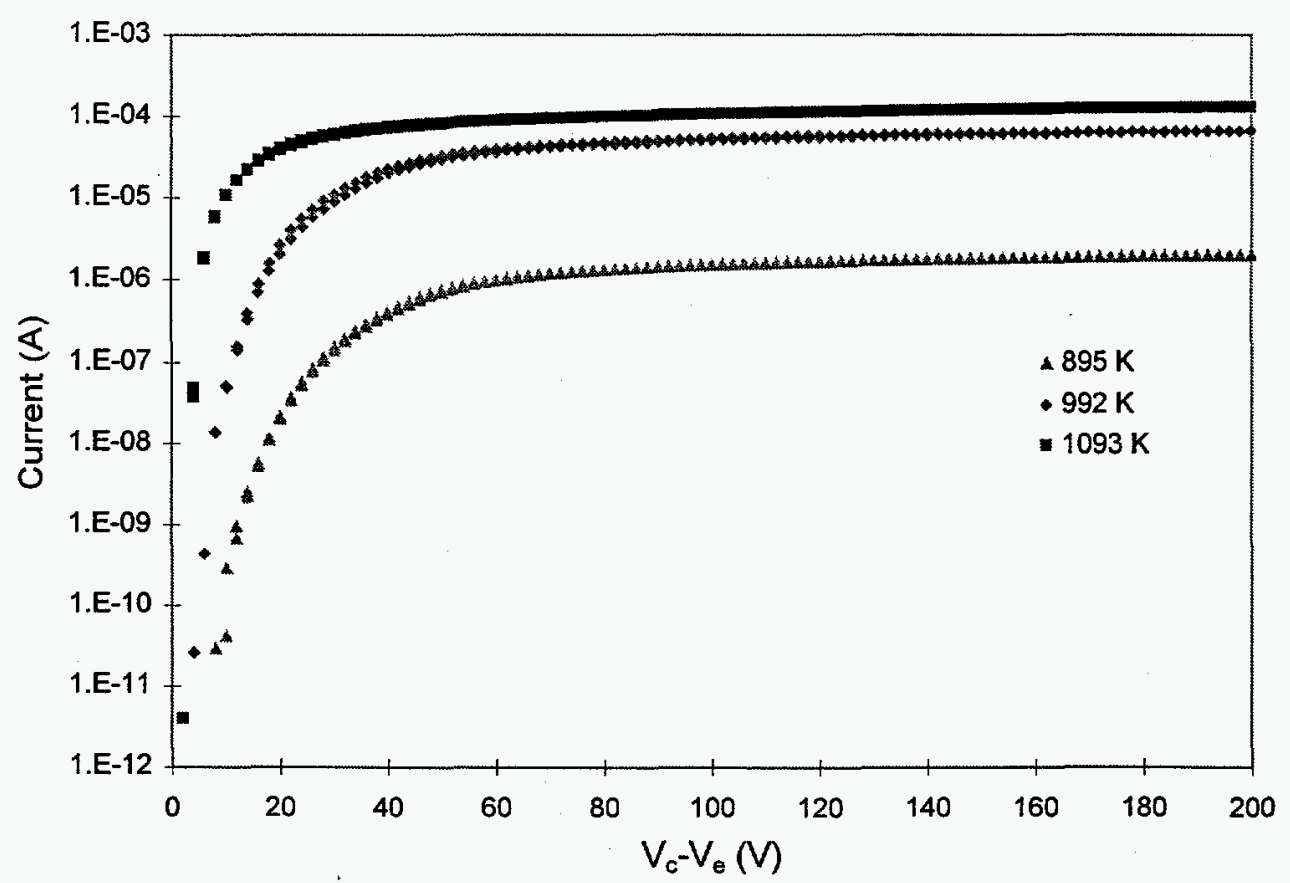

FIGURE 4. Variation in emitter current with diode voltage (collector, $\mathrm{V}_{\mathrm{c}}-$ emitter, $\mathrm{V}_{\mathrm{e}}$ ) and emitter temperature. 
of $1 \times 10^{-6} \mathrm{~Pa}$, with a gap spacing of $1 \mathrm{~mm}$ and in a direct current mode. The curves show expected diode characteristics with a nearly zero current region corresponding to the work function difference of the emitter and collector, a linear region of retarded mode operation, a decrease in current rise with diode voltage indicative of space charge, and finally a slow rise in current with voltage evidence of saturation. Schottky analysis of the saturation region (Hatsopoulos, 1979) for a series of temperatures ranging from 895 to $1074 \mathrm{~K}$ yield a work function $(\phi)$ of $1.8 \mathrm{eV}$ and an apparent emission constant $\left(A^{*}\right)$ of $36 \mathrm{~mA} \cdot \mathrm{cm}^{-2} \cdot \mathrm{K}^{-2}$. Similar values were obtained for a Therm-8 sample. These $\phi$ and $A^{*}$ values are considerably larger and smaller, respectively, than those found for top layer scandate cathodes (Gartner, 1997). Although these values are based on the full voltage drop across the diode, we find that space charge correction (Hasker, 1989) produces a minimal change indicating true limited emission from the cathode. We also find that the current output of these emitters is not highly stable with time, resulting in eventual decreases. The low emission characteristics of these films could be the result of preferential emission from the localized hydroxide surface features.

The instability of these bi-layer films suggests some alternate strategies for improving emitter film performance. Sputter deposition allows for a full range of tuning of the film structure, including a finer intermixing of the barium and scandia phases. One way of achieving this mixing is to deposit very thin alternating layers, resulting in a modulated composition. Modulation should provide the shortest diffusion distances and allow for the formation of scandia particles imbedded in an alkaline earth oxide matrix. Thin enough layers could result in the formation of barium and strontium scandate phases (Kwestroo, 1982). Thin layers would also impede the formation of the columnar crystalline structure presumed to be responsible for $\mathrm{H}_{2} \mathrm{O}$ permeation and eventual hydroxide formation. Recent attempts at modulated films appear to produce greater film stability based on the lack of morphology development with atmospheric exposure.

\section{CONCLUSIONS}

$\mathrm{RF}$ sputtering has been used to deposit thin film BSCO emitters. These films have been shown to be electron emissive at temperatures as low as $900 \mathrm{~K}$ without the need for elevated temperature activation. The direct deposition of oxides eliminates the possibility of condensable gases like $\mathrm{CO}_{2}$ producing increased leakage current between the electrodes when used in a sealed configuration. We measure a reasonably low work function of $1.8 \mathrm{eV}$ and an apparent emission constant of $36 \mathrm{~mA} \cdot \mathrm{cm}^{-2} \cdot \mathrm{K}^{-2}$. The primary barrier to high current density appears to be the instability toward atmospheric exposure of the as-deposited bi-layer film. We find best performance for films that retain as much of the barrier scandia capping layer at the outer surface. The key to improved film stability and optimized properties may be in a higher degree of intermixing between barium and scandia phases.

\section{ACKNOWLEDGMENTS}

Sandia is a multiprogram laboratory operated by Sandia Corporation, a Lockheed Martin Company, for the United States Department of Energy under Contract No. DE-AC04-94AL85000.

\section{REFERENCES}

King, D.B., Fleming, J.G., and Walko, R.J., "The Potential of Vacuum Microelectronics for Space Reactor Applications," in Twelfth Symposium on Space Nuclear Power and Propulsion, edited by M.S. El-Genk, AIP Conference Proceedings \#324, 1995, pp. 19-25.

Thomas, R.E., Gibson, J.W., Haas, G.A., and Abrams, R.H., IEEE Trans. Electron Dev. 37(3), 850-861 (1990).

Saito, M., Suzuki, R., Fukuyama, K., Wantanabe, K., Sano, K., and Nakanishi, H., IEEE Trans. Electron Dev. 37(12), 2605-2610 (1990).

Gartner, G., Geittner, P., Lydtin, H., and Ritz, A., Appl. Surf. Sci. 111, 11-17 (1997).

Zavadil, K.R., and Ing, J.L., "Electron Induced Surface Chemistry at the Cs/Sapphire Interface," in Space Technology and Applications Forum, edited by M.S. El-Genk, AIP Conference Proceedings \#361, 1996, pp. 11891194. 
Hatsopoulos, G.N., and Gyftopoulos, E.P., Themionic Energy Conversion: Volume II: Theory, Technology and Application, Cambridge, MA, MIT Press, 1979, pp. 269-270.

Hasker, J., and Van Dorst, P.A.M., IEEE Trans. Electron Dev. 36(1), 201-208 (1989).

Kwestroo, W., Langereis, C. and Nabben, H., Mater. Res. Bull. 17(5), 641-646 (1982). 